\title{
Review
}

แแแแแแแแแแแแแแแแแแแแแแแแ

\section{Charting the Trends in Nuclear Techniques for Analysis of Inorganic Environmental Pollutants ${ }^{\dagger}$}

\author{
T. BRAUN \\ Institute of Inorganic and Analytical Chemistry, \\ L. Eötvös University \\ P.O. Box 123, 1443 Budapest, Hungary
}

\begin{abstract}
Publications in Analytical Abstracts in the period 1975-1984 and papers presented at the Modern Trends in Activation Analysis international conferences series in the period 1961-1986 have been used as an empirical basis for assessing general trends in research and publication activity. Some ebbs and flows in the specialty of instrumental technqiues for analysis of environmental trace pollutants are revealed by a statistical analysis of the publications.
\end{abstract}

\section{Introduction}

"This paper provides my personal opinion on the status (the trends) of ............... its present strengths, and its weaknesses. I also speculate on what the future will provide and indicate where the research opportunities appear to be".

The previous sentence is a typical one from the analytical chemistry subject literature frequently found in introductions to papers dealing with the status, trends, progresses, growth, etc. of research topics or specialties.

Most of these papers, written by well recognized individuals, are based on common shared insights, casual impressions and estimations, but they seem in general to lack a solid empirical base.

Therefore, this paper attempts to identify and delineate empirically the major areas and topics of research in the specialty of analytical chemistry of inorganic trace pollutants with special emphasis to nuclear techniques, over the past ten years (with some extension back up to 1961) and tries to find out whether there have been remarkable ebbs and flows in that specialty. This can be important for several

\footnotetext{
†核・放射線を利用する無機環境污染分析の動向。 T.ブラウン：エートベース大学無機分析化学研 究室, ハンガリー,ブタペスト市 1443。
}

reasons. It can pinpoint the boundary between what we know and what we do not know. It can help locate the "research fronts" and "hot topics". The goal of the effort is to chart comparatively of what has been studied and to follow the trendline of those topics. It is certainly time to take stock, to see where research in this specialty has been in the past, currently is, and seems to be heading.

Many different approaches can be taken in the evaluation of trends in disciplines, specialties and smaller aggregates (as research topics), ranging from semi-quantitative case studies ${ }^{1)}$ to studies where one or more characteristics of the discipline and specialties and their interrelationship are examined quantitatively ${ }^{2,3}$.

In this paper our focus is more narrow. We examine patterns of article production and some related statistical materials. Before we can begin, however, we must spend some words on prior items, such as how a research specialty can be operationally defined and which questions our analysis addreses.

The term "research specialty" has unfortunately, several referents in technical and popular usage. Rather than debate the advantages and disadvantages of different conceptualizations here, we will instead indicate how we have used the term "specialty" and why we think that "nuclear techniques for analysis of 
inorganic environmental pollutants" is a specialty.

In our view a specialty is a substantive division of a discipline or broad field which has been made by the members of the field themselves primarily on the basis of perceived differences in scientific content. Specialties do, sometimes become institutionalized or socially ratified. By "socially ratified" we mean that arround the substantive area that has been set apart there grows an informal social organization and a recognition by those working in the substantive area that they are members, even if only in a limited sense, of this informal social entity. In the most institutionalized specialties researchers come to identify themselves as members and give the name of their specialty when asked about their professional identifications.

Our analysis addressed three related questions:

(1) Which instrumental methods have been emphasized most in the analysis of environmental trace pollutants?

(2) Which topics have been researched most?

(3) Have there been subfields characterized by growth or decline?

The basic assumption these questions are based on is that there is a strong correlation between research and publication activity in the specialty we are assessing.

\section{The Analysis}

Initially, various review journals were examined to ascertain how best literature trends in nuclear techniques for analysis of inorganic trace pollutants could be determined. Another possibility considered was a computer scan of the Science Citation Index (ISI, Philadelphia, USA) data base searching for key "title words", Unfortunately, many papers would have been overlooked, since their titles do not always utilize the vital key words.

Consequently, the articles in the Analytical Abstracts were scanned and a data base of about 7000 papers was manually built. From these data, the percent of the literature represented by each of the headings selected for this study could be reasonably ascertained. In a paper pub- lished in 1982, Lyon ${ }^{4}$ analyzed some trends of the field of nuclear analytical techniques as reflected in the distribution of papers at the Modern Trends in Activation Analysis conferences. In the present study an extension of that analysis has been made by collecting and charting data as reflected in the full set of the Modern Trends in Activation Analysis conference series. Most of the proceedings of these conferences were published in the Journal of Radioanalytical Chemistry".

Such material taken together provide a rich collection of data which can be manipulated and analysed to yield useful intelligence about research events and patterns.

\section{Results and Discussion}

Table 1 shows that in the period 1975-1984 five instrumental methods (atomic absorption spectrometry, gas chromatography, high performance liquid chromatography (HPLC), potentiometry i.e. ion selective electrodes and spectrophotometry) predominate in the research and publication activity of the specialty. The right side of Fig. 1 indicates that by merging the different individual instrumental methods into more general procedural groups the ranking is as follows: chromatography, spectrometry, electroanalysis, nuclear analysis. In a study published in 1986, Braun ${ }^{\text {6) }}$ ranked the top advances in analytical chemistry 1935-1985 on the basis of a statistical analysis of the opinion of the members of the editorial boards of the major analytical chemistry journals (gatekeepers). That ranking is shown on the left side

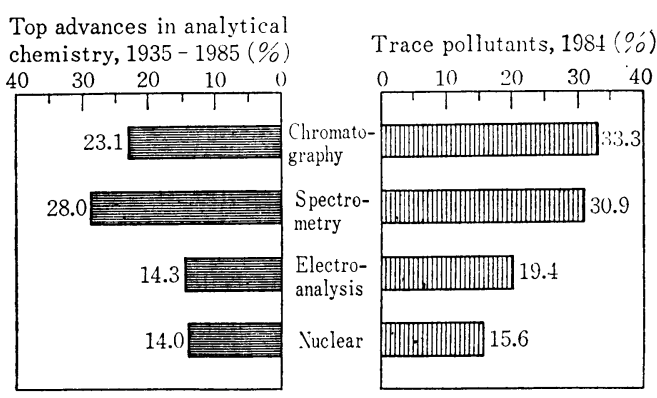

Fig. 1 Comparative charting of publications on instrumental techniques for analysis of environmental trace pollutants and of gatekeeper consensus on the top advances in analytical chemistry 1935-1985. 
Table 1 Instrumental methods in the analysis of trace environmental pollutants

\begin{tabular}{|c|c|c|c|c|}
\hline \multirow{2}{*}{ Method } & \multicolumn{4}{|c|}{ Percentage of total } \\
\hline & 1978 & 1980 & 1982 & 1984 \\
\hline 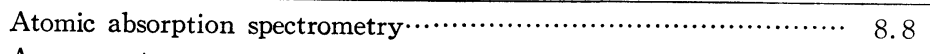 & 9.2 & 10.4 & 9.8 & 10.6 \\
\hline Amperometry $\cdots \cdots \cdots \cdots \cdots$ & $\cdots \cdot$ & & & .• 1.1 \\
\hline Auger spectrometry $\cdots \cdots \cdots$ & & & & $\cdot 0.6$ \\
\hline Chromatography $\cdots \cdots \cdots \cdots$ & & & & 3.9 \\
\hline Conductometry $\cdots \ldots \ldots \ldots \ldots \ldots \ldots \ldots$ & & & & $\begin{array}{ll}\cdots & 0.2\end{array}$ \\
\hline Coulometry $\cdots \ldots \ldots \ldots \ldots \ldots$ & & & & .. 2.2 \\
\hline Electron microprobe...$\ldots \ldots \ldots$ & & & & $\begin{array}{ll}\cdots & 0.6\end{array}$ \\
\hline Fluorimetry $\cdots \ldots \ldots \ldots \ldots \ldots \ldots \ldots \ldots \ldots \ldots \ldots \ldots \ldots$ & & & & -. 2.0 \\
\hline 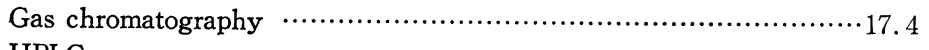 & 16.9 & 16.3 & 14.4 & 12.8 \\
\hline 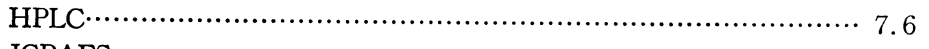 & 8.1 & 9.5 & 11.3 & 12.2 \\
\hline 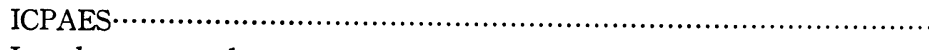 & & & & .. 2.2 \\
\hline Ion chromatography $\ldots \ldots \ldots \ldots \ldots \ldots \ldots \ldots$ & & & & .. 2.7 \\
\hline 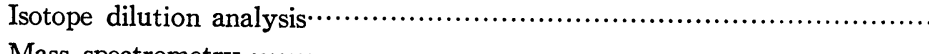 & & & &.$\cdot 3.3$ \\
\hline 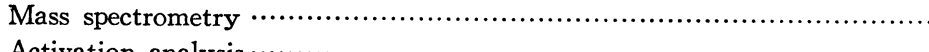 & & 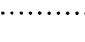 & $\cdots$ & .. 3.1 \\
\hline 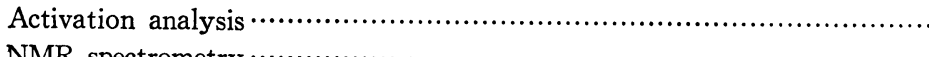 & & & & .. 5.4 \\
\hline NMR spectrometry $\cdots \cdots \cdots \cdots \cdots \cdots \cdots$ & & & $\cdots$ & .. 1.1 \\
\hline 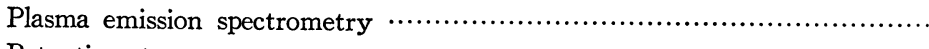 & & & 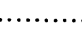 & 0.6 \\
\hline 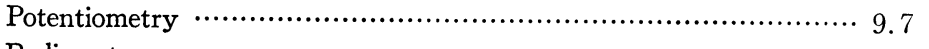 & 8.8 & 10.1 & 9.4 & 10.0 \\
\hline 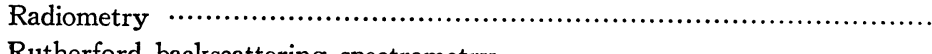 & & & & -. 2.8 \\
\hline 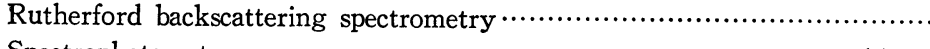 & & … & $\cdots \cdots$ & 0.6 \\
\hline 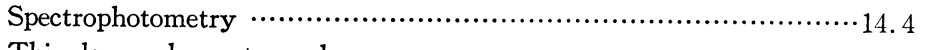 & 12.8 & 12.0 & 12.2 & 10.1 \\
\hline 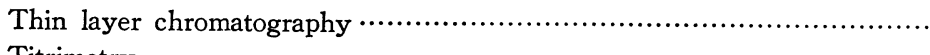 & & & & 1.7 \\
\hline Titrimetry $\cdots \cdots \cdots \cdots \cdots \cdots \cdots \cdots \cdots \cdots \cdots$ & & & & 2.2 \\
\hline Voltametry $\cdots \ldots \ldots \ldots \ldots \ldots \ldots$ & & & & 3.9 \\
\hline XRF spectrometry $\cdots \cdots \cdots \cdots \cdots$ & & & & 4.1 \\
\hline
\end{tabular}

Source: Analytical Abstracts (UK)

Table 2 Instrumental methods used in an IAEA (64 laboratories) round robin intercomparison of the determination of 16 elements in environmental water samples (1977)

\begin{tabular}{lc}
\hline \multicolumn{1}{c}{ Instrumental method } & $\%$ of use \\
\hline Activation analysis & 21.9 \\
Atomic absorption & 53.0 \\
Fluorimetry & 2.6 \\
Emission spectrometry & 7.3 \\
Colorimetry, spectrophotometry & 5.3 \\
XRF & 0.3 \\
Mass spectrometry & 4.7 \\
Voltametry & 4.4 \\
Not communicated & 0.5 \\
\hline
\end{tabular}

of Fig. 1. It is interesting to see that the two rankings correlate quite well. This seems to indicate that there was a tendency in the specialty of instrumental analysis of environmental trace pollutants to use always the top advances in the general field of analytical chemistry.
An example of the real use of instrumental methods for a well defined purpose (the determination of trace metal pollutants in environmental water samples) is shown in Table 2 . There is a fairly good correlation between that use and publication statistics (Table 1). Table 3 presents the results of an instrument inventory at university departments in the US. Although there is no indication on the extent these instruments have been used for different trace analytical purposes (including the analysis of environmental trace pollutants) these data correlate also quite well with the data in Table 1. By comparing the data of Table 4 on the concentration of trace metals in seawater with some matched data on the detection limits for trace elements by different instrumental methods (Table 5) it will be evident that in a number of cases preconcentration of the trace pollutants before instrumental determination is a necessity? . 
Table 3 Instrument inventory at university departments* (Mean age of instruments: 9.03 years)

\begin{tabular}{lc}
\hline \multicolumn{1}{c}{ Instrument } & $\begin{array}{c}\text { Availability } \\
(\%)\end{array}$ \\
\hline UV-VIS spectrometer & 18.87 \\
Gas chromatograph & 15.28 \\
NMR spectrometer & 12.90 \\
Infrared spectrometer & 12.10 \\
Liquid chromatograph & 7.87 \\
Atomic absorption spectrometer & 4.45 \\
ESR/EPR & 3.18 \\
Fluorimeter & 3.06 \\
X-ray difractometer & 2.72 \\
Liquid scintillation spectrometer & 2.31 \\
Single-crystal X-ray difractometer & 1.27 \\
Raman spectrometer & 1.27 \\
Differential scanning calorimeter & 1.21 \\
Quadrupole mass spectrometer & 0.92 \\
Optical emission spectrometer & 0.75 \\
Gamma spectrometer & 0.75 \\
X-ray fluorescence spectrometer & 0.46 \\
Photoelectron spectrometer & 0.40 \\
ICP spectrometer & 0.28 \\
Mössbauer spectrometer & 0.22 \\
EXAFS & 0.11 \\
Ion chromatograph & 0.11 \\
\hline
\end{tabular}

* Based on a survey at 116 chemistry departments in the USA (in 1982)

Data extracted from Anal. Chem., 56, 1225 (1984)

That's why we tried to find out which major mathods were used for the preconcentration of inorganic trace pollutants and also tried to follow the publication trends on these methods during the last 10 years. The results are pre-
Table 4 Trace metal concentrations in seawater $(\mu \mathrm{g} / \mathrm{l})$

\begin{tabular}{lccl}
\hline & Brewer $(1975)^{*}$ & NASS-1** & ICES-5*** \\
\hline $\mathrm{As}$ & 3.7 & 1.65 & 1.4 \\
$\mathrm{Cd}$ & 0.1 & 0.029 & 0.020 \\
$\mathrm{Cr}$ & 0.3 & 0.184 & 0.08 \\
$\mathrm{Co}$ & 0.05 & 0.004 & 0.004 \\
$\mathrm{Cu}$ & 0.5 & 0.099 & 0.123 \\
$\mathrm{Fe}$ & 2 & 0.192 & 0.376 \\
$\mathrm{~Pb}$ & 0.03 & 0.039 & 0.049 \\
$\mathrm{Mn}$ & 0.2 & 0.022 & 0.240 \\
$\mathrm{Mo}$ & 10 & 11.5 & - \\
$\mathrm{Ni}$ & 1.7 & 0.257 & 0.202 \\
$\mathrm{Zn}$ & 5 & 0.159 & 0.392 \\
\hline
\end{tabular}

* Brewer, P.G.: "Chemical Oceanography", Vol. 1, 2nd ed., chap. 7. Riley, S.P. and Skirrow, G., Eds., Academic Press, New York (1975)

** Berman, S.S., Sturgeon, R.E., Desaulniers, J. A.H. and Mykytiuk, A.P.: Mar. Pollut. Bull., 14, 69 (1983)

*** Berman, S.S., Mykytiuk, A.P., Yeats, P.A. and Bewers, J.M.: International Council for the Exploration of the Sea, Report CM1983/ E: 24 (1983)

sented in Fig. 2.

The term "speciation" has come into a certain degree of use in the past few years in connection with environmental analysis. As applied, the term means identification of inorganic, organometallic, or organic compounds actually present in the environment. This is not always an easy (or even a possible) task. The term speciation really draws attention to the distinction between measuring the total concentration of an element and measuring the concentration of each of its

Table 5 The determination limits of instrumental methods

\begin{tabular}{|c|c|c|c|c|c|c|}
\hline \multirow{2}{*}{ Method } & \multirow{2}{*}{$\begin{array}{l}\text { Lamotte, } \\
\text { Revel* } \\
\text { (g) }\end{array}$} & \multicolumn{2}{|c|}{ Baudin $^{* *}$} & \multirow{2}{*}{$\begin{array}{c}\text { Lieser*** } \\
(\mathrm{g} / \mathrm{g})\end{array}$} & \multirow{2}{*}{$\begin{array}{c}\text { Precision } \\
(\%)\end{array}$} & \multirow{2}{*}{ Cost } \\
\hline & & (ppm) & $(\mathrm{mol} / \mathrm{l})$ & & & \\
\hline Atomic absorption (flameless) & $10^{-5}-10^{-7}$ & $10^{-2}-10^{-3}$ & $10^{-8}-10^{-10}$ & $10^{-7}-10^{-11}$ & $2-5$ & low \\
\hline Voltametry & $10^{-6}-10^{-8}$ & $10^{-3}-10^{-4}$ & $10^{-9}-10^{-10}$ & ${ }^{0} 10^{-6}-10^{-9}$ & $2-10$ & medium \\
\hline Inductively coupled plasma emission(ICP) & $10^{-5}-10^{-8}$ & $10^{-1}-10^{-2}$ & $10^{-7}-10^{-9}$ & $10^{-6}-10^{-9}$ & $5-50$ & high \\
\hline Spark mass spectrometry & $10^{-6}-10^{-9}$ & $10^{-2}-10^{-3}$ & $10^{-8}-10^{-10}$ & ${ }^{0} 10^{-6}-10^{-8}$ & $5-20$ & high \\
\hline Spectrophotometry, fluorimetry & - & $0.1-10$ & $10^{-5}-10^{-7}$ & $10^{-4}-10^{-6}$ & $1-5$ & low \\
\hline Neutron activation analysis & $10^{-7}-10^{-12}$ & $210^{-3}-10^{-4}$ & $10^{-9}-10^{-10}$ & $10^{-6}-10^{-11}$ & $2-20$ & high \\
\hline $\mathrm{X}$-ray fluorescence (XRF) & $10^{-3}-10^{-5}$ & $1-100$ & $10^{-2}-10^{-4}$ & $10^{-4}-10^{-6}$ & $1-2$ & high \\
\hline Proton induced X-ray emission (PIXE) & - & - & $10^{-8}-10^{-10}$ & $0 \quad-$ & - & high \\
\hline
\end{tabular}

* Lamotte, A." and Revel, G.: Analysis, 12, 423-431 (1984)

** Baudin, G.: J. Radioanal. Chem., 37, $119-139$ (1977)

*** Lieser, K.H. : Kontakte, (2), 56-64 (1984) 


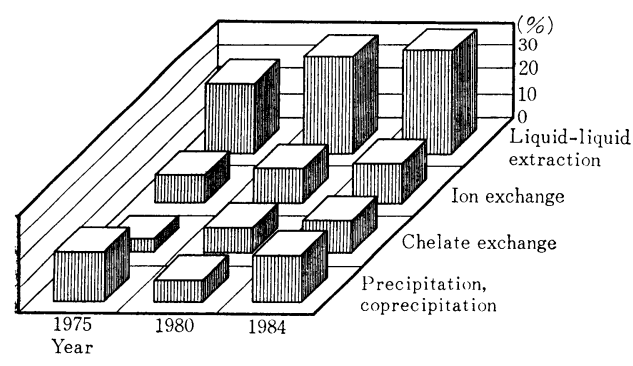

Fig. 2 Publication trends on preconcentration methods of inorganic trace pollutants 1975-1984.

Table 6 Speciation of $\mathrm{Cu}, \mathrm{Pb}, \mathrm{Zn}$ and $\mathrm{Cd}$ with major anions in sea water*

\begin{tabular}{lcccc}
\hline \multirow{2}{*}{ Complex } & \multicolumn{5}{c}{$\beta_{n}{ }^{*}[\mathrm{~L}]^{n}$} \\
\cline { 2 - 5 } & $\mathrm{Cu}$ & $\mathrm{Pb}$ & $\mathrm{Zn}$ & $\mathrm{Cd}$ \\
\hline $\mathrm{MCl}^{+}$ & 0.43 & 4.2 & $\mathbf{0 . 8 4}$ & 11.7 \\
$\mathrm{MCl}_{2}$ & - & 5.7 & - & $\mathbf{1 3 . 9}$ \\
$\mathrm{MCO}_{3}$ & $\mathbf{5 3 . 7}$ & $\mathbf{2 4}$ & 0.2 & 0.08 \\
${\mathrm{M}\left(\mathrm{CO}_{3}\right)_{2}{ }^{2-}}_{\mathrm{MOH}}$ & 7.6 & 7.2 & - & - \\
$\mathrm{M}(\mathrm{OH})_{2}$ & 6.9 & 3.2 & 0.1 & 0.006 \\
$\mathrm{MB}(\mathrm{OH})_{4}{ }^{+}$ & 4.0 & 0.2 & - & - \\
$\mathrm{M}\left[\mathrm{B}(\mathrm{OH})_{4}\right]_{2}$ & 0.003 & $4 \times 10^{-5}$ & $5 \times 10^{-6}$ & $10^{-6}$ \\
\hline
\end{tabular}

Obs. : -When $\beta_{n}{ }^{*}[\mathrm{~L}]^{n}$ is greater than unity, the concentration of the complex ion is greater than that of the free ion.

* van den Berg, C.M.G.: Anal. Proc., 20, (9) 458 (1983)

Table 7 Speciation of $\mathrm{Cu}, \mathrm{Pb}, \mathrm{Zn}$ and $\mathrm{Cd}$ in sea water containing complexing ligands*

\begin{tabular}{lrrrr}
\hline \multirow{2}{*}{$\begin{array}{c}\text { Type of } \\
\text { interaction }\end{array}$} & $\mathrm{Cu}$ & $\mathrm{Pb}$ & $\mathrm{Zn}$ & $\mathrm{Cd}$ \\
\cline { 2 - 5 } & 93 & 81 & 75 & 16 \\
\hline Oaganic**-metal & 7 & 19 & 25 & 84 \\
Inorganic-metal & 7 Element (\%) \\
\hline * van den Berg, C.M.G.: & Anal. & Proc., 20, (9) \\
458 (1983) & & & \\
** Organic-metal interaction for & $\mathrm{Pb}, \mathrm{Zn}$ and $\mathrm{Cd}$ \\
modelled on EDTA(experimental value for $\mathrm{Cu})$.
\end{tabular}

chemical forms.

Tables 6 and 7 present some quantitative examples of the influence of speciation on the concentration of trace elements in sea water samples. Figures 3 and 4 exemplify on the other hand that speciation in case of use of nuclear techniques has always to be preceded

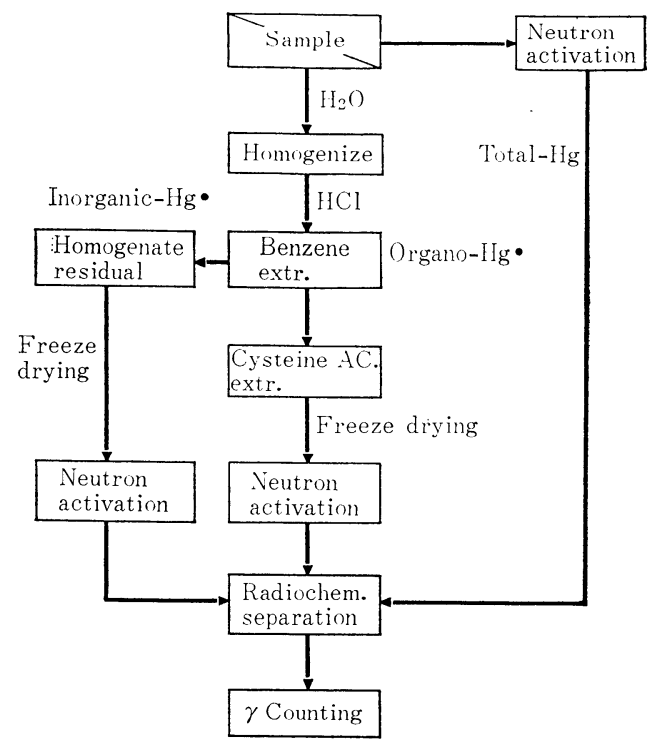

Fig. 3 Flow chart for organo-mercurials and inorganic-mercury determination in environmental waters by neutron activation analysis.

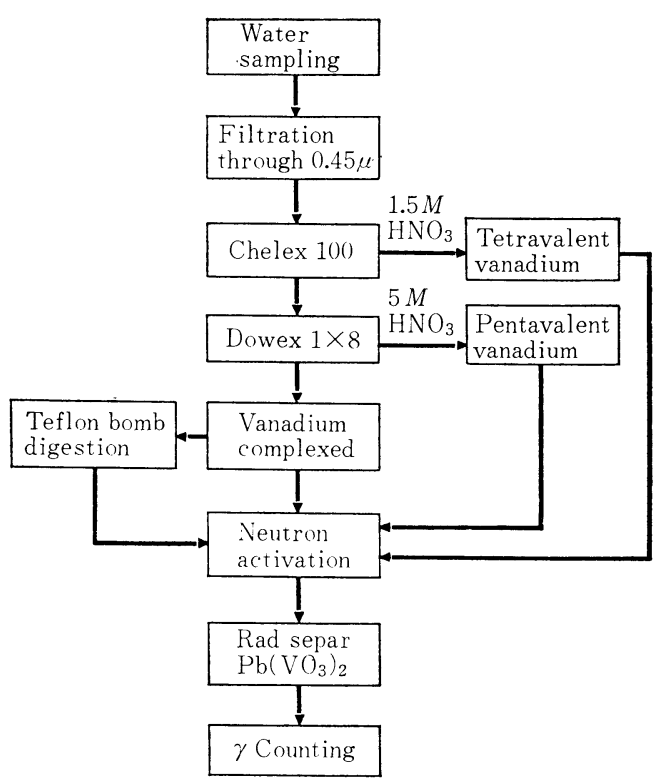

Fig. 4 Flow chart for vanadium speciation in environmental waters with subsequent determination by neutron activation analysis.

by separation and preconcentration procedures. Taking into account the abovementioned, a statistical analysis has been made for the 1975- 


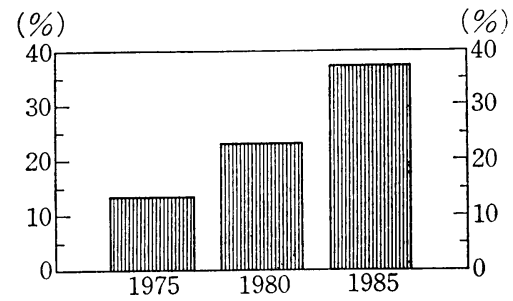

Fig. 5 Trends in publication of instrumental methods for the determination of physico-chemical forms (speciation) of inorganic trace pollutants, 1975-1985.

1984 period, in order to find out if there is a growth tendency in the publication activity related to speciation in the analysis of inorganic trace pollutants.

The results are presented in Fig. 5. All the abovementioned data (included in Charts No. 1-5 and in Tables 1-6) are trying to help the reader to have a empirically substantiated quantitative view on the research and publication activity in the specialty of instrumental techniques for determination of environmental trace pollutants and to gain an image on the rank of nuclear analytical techniques within the general framework of instrumental methodologies. They also contribute to having an indication on the trends in publication activities within these methodologies.

Turning now to activation analysis, which, according to Tables 1 and 3 , is without doubt the most frequently used nuclear technique for the analysis of inorganic trace pollutants, we were trying to have a statistical evaluation of the papers presented at the Modern Trends in Activation Analysis conference series. According to Lyon $^{4}$ these have been the broadest based and longest running series of all activation analysis conferences. "From the modest beginning in 1961 the conference has grown in size, prestige and interest .... it seems established that the quality of papers at neutron activation analysis (NAA) conferences in quite high ... ${ }^{4}$ )" The classification to techniques and subject matter originally used by Lyon $^{4}$ has been adopted in this study and Figs. 6 and 7 are derived from Lyon's graphs with our own additional data for the $1981^{\text {s) }}$ and 1986 conferences. The 1986 proceedings are not yet published but at the date of compiling this paper (January, 1986)

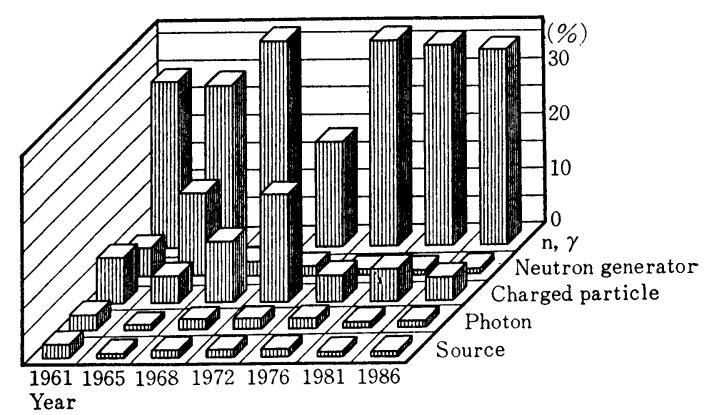

Fig. 6 Publication trends by technique at the Modern Trends in Activation Analysis conference series 1961-1986.

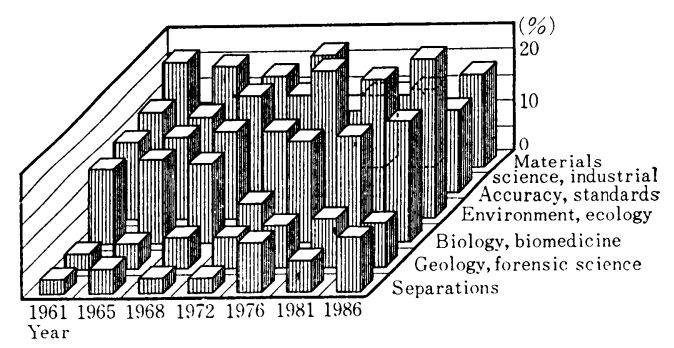

Fig. 7 Publication trends by subject at the Modern Trends in Activation Analysis conference series 1961-1986.

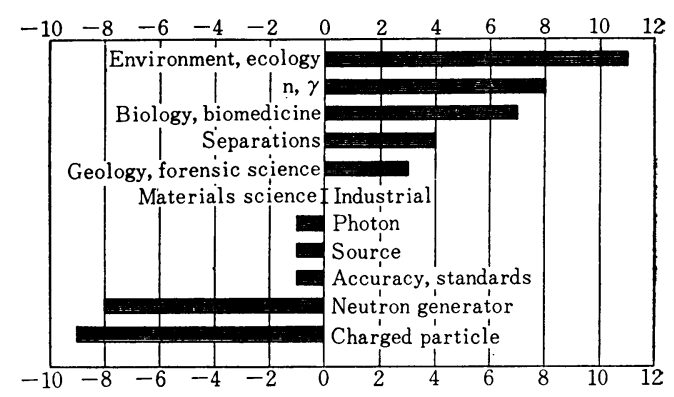

Fig. 8 Relative trends in research and publication activity at the Modern Trends in Activation Analysis conference series, 1961-1981 overage versus 1986.

the preliminary program of the conference with the full title of all papers to be presented has been already available. Figure 8 shows the relative research and publication trends observed at the 1986 Modern Trends in Activation Analysis as compared to the average data for all the previous conferences.

When evaluating these data it is important to notice that after a very remarkable unintercrupted exponential growth rate at the fantastic doubling time of 2.2 years in the period $1936-$ 


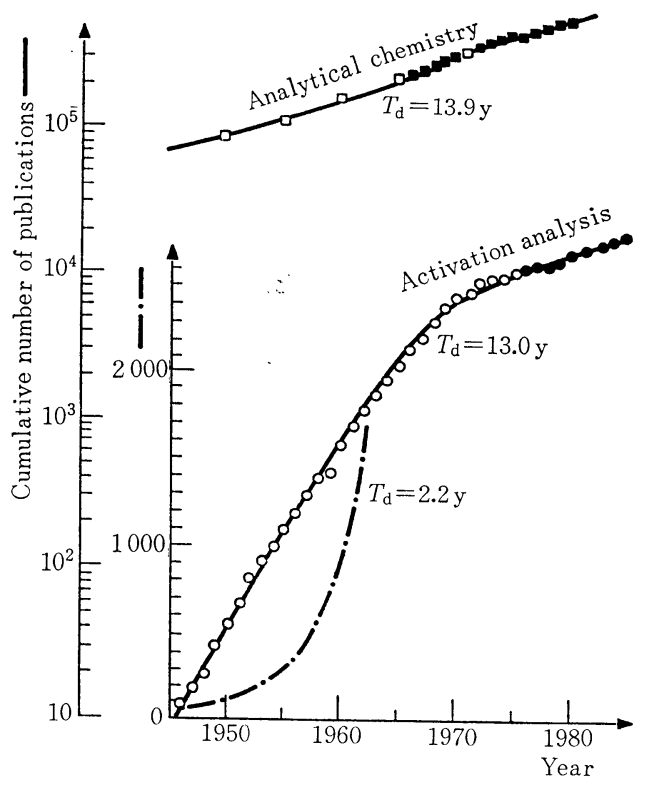

Fig. 9 Cummulative growth rate of publications on activation analysis and on analytical chemistry, 1936-1985.

1970 (15 doubling times), the growth rate of publication activity in activation analysis slowed down to a doubling time of 13.0 years (Fig. 9). As seen in the figure this is quite near to the value shown for the growth rate of publication activity in general analytical chemistry (13.9 years $)^{2), 9)}$.

This paper presents a quite comprehensive amount of empirical data on the research and publication activity in the field of instrumental techniques for analysis of environmental trace pollutants. The data are collected in tables and charts with very brief interpretation. That's because the reader is invited and encouraged to examine the tables and charts and see what additional comments, conclusions and trends he/she can observe.

\section{Additional Future}

After restricting the previous parts of this paper to empirical evidence, in what follows we will take the liberty of outlining some speculations concerning a different aspect of instrumental techniques for on-site analysis of environmental pollutants with some emphasis on nuclear analytical techniques. One of the most promising rising aspects in on-site analysis seems to be that of chemical sensing in the environment Chemical sensor is the key-word in this respect. "The term chemical sensor covers a wide range of devices. Depending on the background of the individual using the term, chemical sensor may conjure up an image of a chemical transducer the size of a pin-head, or a piece of hardware weighing many kilograms ...... Sensors may be located anywhere in the environment from the North Sea to the human bloodstream. Basically, all chemical sensors have similar characteristics. Somewhere in the sensor a transducer exists that transforms the desired chemical property of the analyte (usually concentration) into an electrical signal. Some transducers are inherently selective ..... On the other hand many of the transducers are not selective, and must be rendered so ..... Not only must a chemical sensor respond to a particular molecular species, or group of related compounds, but also it must discriminate between the target analyte and the full range of other chemical species in the immediate environment."10)

The overhelming majority of chemical sensors can be grouped around two types of devices:

$$
\begin{aligned}
& \text {-electrodes } \\
& \text {-optrodes }
\end{aligned}
$$

There is no need to define the first type. Shortly, "an optrode is a device involving a reagent phase on the end of a fiber optic. In operation, interaction with analyte leads to a change in optical properties of the reagent phase, which is probed and detected through the fiber optic. Depending on the particular device, the optical property measured can be absorbance, reflectance, luminescence or something else."11)

There seems to be a certain chance that the abovementioned two types of devices could be supplemented in the future by a third one we suggest to be called:

\section{-nucleotrodes}

Promising preliminary results ${ }^{12)}$ seem to indicate that such type of sensors can be built e.g. in combination with XRF sensing.

\section{References}

1) Braun, T. and Lyon, W.S.: Fresenius $Z$. Anal. Chem., 319, 74-77 (1984) 
2) Braun, T. and Bujdosó, E.: CRC Critical Reviews in Analytical Chemistry, 13, 223312 (1982)

3) Braun, T., Bujdosó, E. and Schubert, E.: "The Literature of Analytical Chemistry: Trends and Patterns", CRC Press, Florida, to be published in 1986 .

4) Lyon, W.S.: J. Radioanal. Chem., 69, 107 (1982)

5) Proceedings of the 1981 International Conference on Modern Trends in Activation Analysis, Toronto, Canada, June 1519, 1981. J. Radioanal. Chem., 69, 1-497 (1982); 70, 1-556 (1982); 71, 1-586
(1982); 72, 1-736 (1982)

6) Braun, T.: Fresenius Z. Anal. Chem., to be published (1986)

7) Mizuike, A.: "Enrichment Techniques for Inorganic Trace Analysis", SpringerVerlag, Berlin (1983)

8) Braman, R.S.: Chemical Speciation

9) Girardi, F.: J. Radioanal. Chem., 69, 15 (1982)

10) Edmonds, T.E.: Trends Anal. Chem., 4, 220 (1985)

11) Seitz, W.R.: Anal. Chem., 56, 16A (1984)

12) Braun, T.: unpublished results 